\title{
Respiratory System-The Port of Entry of SARS-COV-2 with Special Reference to Aerosol Management
}

\author{
Muralidhar Kanchi', Moumita Chakraborthy'2, Amal T J Joseph ${ }^{3}$, P Sibiya Poonely Chacko ${ }^{3}$ \\ DDepartment of Anaesthesia and Intensive Care, Narayana Institute of Cardiac Sciences, ${ }^{2}$ Narayana Health Foundations, \\ ${ }^{3}$ Department of Respiratory Therapy, Narayana Institute of Allied Health Sciences, Narayana Health City, Bengaluru, Karnataka, India
}

\section{Abstract}

The outbreak of novel coronavirus disease (COVID-19) caused by the severe acute respiratory syndrome coronavirus-2 (SARS-CoV-2) has led to a global pandemic of unprecedented proportions. Management of patients infected with COVID-19 has led to a great risk of hospital-based transmission of infection to health-care professionals (HCPs). The HCPs at various levels in a multispecialty health-care setup are at risk of contracting the virus. Those who are involved with performing or assisting in aerosol-generating procedures (AGPs) have a potentially higher risk of developing the infection. The AGPs involve a wide range of procedures such as pulmonary function testing, high-flow oxygen administration, endotracheal intubation, nebulization, application of ventilators, weaning and extubation, bronchoscopy, tracheostomy, and cardiopulmonary resuscitation. Hence, understanding the overall nature of the disease is of vital importance to develop preventive strategies to reduce transmission of the virus through aerosols. This review article intends to elucidate the port of entry associated with SARS-CoV-2 infection and its spread through the AGPs. We also intend to focus on methods to prevent aerosol-related transmission of infection to HCPs by illustrating clinically practiced evidence-based protocol followed in our multispecialty health-care setup.

Keywords: Aerosol-generating procedure, barrier devices in COVID-19, pathophysiology of COVID-19, personal protective equipment, transmission of severe acute respiratory syndrome coronavirus- 2

\section{INTRODUCTION}

In December 2019, an outbreak of COVID-19 disease caused by the severe acute respiratory syndrome coronavirus 2 (SARS-CoV-2) occurred in Wuhan city of China, leading to a global pandemic. ${ }^{[1]}$ Health-care professionals (HCPs) referred to as "frontliners" or "COVID warriors" include clinicians, nurses, respiratory therapists, laboratory technicians, paramedical staff, and housekeeping personnel. Even with adequate personal protective equipment (PPE), HCPs who care for patients with COVID-19 not only remain at increased risk of hospital-based transmission but also may be responsible for community spread of the virus. ${ }^{[2]}$

In this review article, we intend to give a brief summary about the port of entry of SARS-COV-2 and its transmission. We carried out an extensive literature search for a period of 3 months from July 2020 to September 2020. Search engines such as Google Scholar and PUBMED were used to search for relevant articles, using keywords, pathophysiology of

\begin{tabular}{|l|l|}
\hline \multicolumn{3}{|c|}{ Access this article online } \\
\hline Quick Response Code: & Website: \\
\hline & www.ijrc.in \\
\hline & \\
\end{tabular}

COVID-19, transmission of SARS-CoV-2, aerosol-generating procedures (AGPs), PPEs, and barrier devices in COVID-19. We included original articles, insights from case reports, and review articles in our study. We included only full length studies while the studies with only abstracts were not cited. Our main focus is to understand the AGPs and how they can be performed during this COVID era so as to ensure minimal

Address for correspondence: Dr. Muralidhar Kanchi, Department of Anaesthesia and Intensive Care, Narayana Institute of Cardiac Sciences, Narayana Health City, Bengaluru, Karnataka, India. Department of International Health, University of Minnesota, USA. Indian College of Anaesthesiologists, New Delhi, India. Narayana Hrudayalaya Institute of Allied Health Sciences, Bengaluru, Karnataka, India. E-mail: muralidhar.kanchi.dr@narayanahealth.org

This is an open access journal, and articles are distributed under the terms of the Creative Commons Attribution-NonCommercial-ShareAlike 4.0 License, which allows others to remix, tweak, and build upon the work non-commercially, as long as appropriate credit is given and the new creations are licensed under the identical terms.

For reprints contact:WKHLRPMedknow_reprints@wolterskluwer.com

How to cite this article: Kanchi M, Chakraborthy M, Joseph AT, Chacko PS. Respiratory system-the port of entry of SARS-COV-2 with special reference to aerosol management. Indian $\mathrm{J}$ Respir Care 2021; 10:S15-23.

Received: $15-12-2020 \quad$ Revised: 08-02-2021

Accepted: 14-02-2021 Published: 29-04-2021 
Kanchi, et al.: Respiratory system - The port of entry of SARS-COV-2 with special reference to aerosol management

risk to HCPs performing or assisting them. In addition, we highlight the barrier precautions taken for the purpose at our health-care setup.

\section{COVID-19, Symptoms, Port of Entry, and TRANSMISSION}

\section{Symptoms of COVID-19}

COVID-19 disease is principally an illness of the respiratory system, and the main clinical presentation of the disease constitutes pulmonary symptoms. The pulmonary symptoms include fever, dry cough, fatigue, and dyspnea. Other clinical manifestations reported are sore throat, headache, chills, nausea, vomiting, myalgia, nasal congestion, diarrhea, hemoptysis, and conjunctival congestion. ${ }^{[3]}$ In older patients or those with comorbidities, dyspnea may appear at the onset of symptoms, while those who are young and without any comorbidities, dyspnea might occur at a later stage. ${ }^{[4]}$ SARS-CoV-2 infection is not only limited to the respiratory system but also may affect other organs. Extrapulmonary symptoms related to neurological, hepatic, renal, and gastrointestinal dysfunction have also been reported. ${ }^{[5,6]}$

\section{Port of entry}

The main port of entry of SARS-CoV-2 is through the respiratory tract. SARS-CoV-2 is the third coronavirus that is responsible for severe disease in humans to spread globally in the past two decades. ${ }^{[7]}$ The virus manifests its life cycle in five steps, namely: attachment, penetration, biosynthesis, maturation, and release. ${ }^{[8]}$

Angiotensin-converting enzyme 2 (ACE2) was identified as a functional critical receptor for SARS-CoV-2. ${ }^{[9-11]}$ The viral envelope of corona virus consists of spike protein that binds to specific receptor in the lung; ACE is detectable in the entire alveolar capillary network. ACE2 is primarily produced in club cells of distal bronchioles and type 2 pneumocytes in alveolar epithelium. Both cell types are responsible to prevent acute respiratory distress syndrome. However, when the virus binds to the host's body, it tends to downregulate ACE2 enzyme leading to tissue inflammation and fibrosis. ${ }^{[12]}$ ACE2 is also highly expressed in other vital organs such as myocardial cells, kidney, brain, adrenals, small intestine, and urinary bladder. ${ }^{[12-16]}$

\section{Mode of transmission}

SARS-CoV-2 virus is reported to survive in aerosols for $>3 \mathrm{~h}$, ${ }^{[17]}$ leading to a greater need to identify and categorize the areas which are high risk for spread. HCPs are at risk of contracting the virus, especially while performing AGPs. High-risk AGPs are those clinical events that have the potential to generate aerosols that consists of high viral loads, and they pose an elevated risk for acquiring SARS-CoV-2 infection by HCPs. ${ }^{[18]}$ Procedures such as suctioning the airway, intubation, nebulization, noninvasive ventilation (NIV), invasive ventilation, cardiopulmonary resuscitation (CPR), tracheostomy, and bronchoscopy are identified as high-risk AGPs. ${ }^{[18,19]}$
Factors that may lead to an increased risk of transmission during AGPs include duration of exposure, proximity of provider to aerosol, manipulation of high viral load tissue, and aerosolization through the use of energy devices. The ability to limit the transmission of COVID-19, in the health-care setup, involves practicing evidence-based prevention and control measures, of which PPE is a fundamental element. Practicing the use of barrier devices during AGPs also should be considered to prevent transmission.

\section{Aerosols from cough, sneeze, exhalation, and speech}

Respiratory viruses are transmitted by droplets generated during coughing, sneezing, exhalation, and speech. ${ }^{[20]}$ SARS-COV-2 virus spreads through tiny droplets released from the nose and mouth of an infected patient's cough or sneeze. A single cough is said to produce up to 3000 droplets. $^{[21,22]}$ COVID-19 may spread in four ways. The proposed direct transmission ways are by (i) infectious droplets expulsed by coughing or sneezing onto a mucous membrane (mouth, nose, and eyes); (ii) from AGPs; (iii) by direct contact; and (iv) indirect transmission by contact with contaminated surfaces (fomites). ${ }^{[23]}$

The formation of aerosols can be categorized based on diameter. Large droplets are $>100 \mu \mathrm{m}$, medium droplets are 5-10 $\mu \mathrm{m}$, and small droplets or droplet nuclei (aerosols) are $<5 \mu \mathrm{m}$. Large droplets tend to get deposited due to gravity and are responsible for direct transmission and indirect contact transmission. Small droplets (aerosols) are responsible for short and long-range airborne route and also indirect contact transmission. ${ }^{[24]}$

A recent insight by Bourouiba ${ }^{[25]}$ highlighted that the mucosalivary droplets expelled through exhalation, coughs, and sneezes are made of multiphase turbulent gas "cloud" that entrains the ambient air and carries it in the form of clusters. The gas cloud loaded with pathogen-bearing droplets may travel up to 7-8 m. Furthermore, the lifetime of the droplets may extend by a factor of up to 1000 as compared to isolated droplets.

A study by Tang et al. ${ }^{[26]}$ used the schlieren optical method to visualize the speed (flow rate) of a single cough in an indoor setting. The technique involves optical phase gradient encompassing temperature differences. The character of the expelled cough is turbulent jet flow. They reported that without application of mask, the exhaled airflow can be more than $0.5 \mathrm{~m}$ vertically and at initial phase of cough (until $0.1 \mathrm{~s}$ ), the airflow can be $8 \mathrm{~L} / \mathrm{s}$. Speech might also generate a trajectory flow of aerosol responsible for transmission. An experiment conducted by Anfinrud et al. ${ }^{[27]}$ using laser light scattering technique showed that aerosol transmission during speech can traverse a distance of 50-75 $\mathrm{mm}$. The recommended social distancing given by Center for Disease Control and Prevention (CDC) is $2 \mathrm{~m}$. However, some studies observed that the recommendation of $2 \mathrm{~m}$ or 6 feet distance may not be sufficient as droplet transmission can happen beyond $2 \mathrm{~m} \cdot{ }^{[28,29]}$ 
Kanchi, et al.: Respiratory system - The port of entry of SARS-COV-2 with special reference to aerosol management

\section{Aerosol-generating procedures}

Procedures such as CPR, tracheostomy, bronchoscopy, suctioning, intubation, nebulization, NIV, and invasive ventilation are identified as high-risk AGPs. ${ }^{[30,31]}$ Selection and utilization of appropriate respiratory PPEs are of utmost priority in this current COVID-19 pandemic. How significant is the role of transmission related to the AGPs as compared to other modes of transmission in the spread of SARS-COV-2 remains unclear. HCPs pose a high risk of acquiring preventable infections during various AGPs attributing to the lack of clarity of risks associated with various procedures. ${ }^{[32,33]}$

\section{Oxygen delivery devices}

In normal spontaneously breathing patients, application of a simple face mask may generate aerosols that may spread up to $0.2 \mathrm{~m} \cdot{ }^{[34]}$ Maximum exhaled air distance using a simple face mask at a flow of $4 \mathrm{~L} / \mathrm{min}$ is $0.20 \mathrm{~m}$. When flow is increased from $4 \mathrm{~L} / \mathrm{min}$ to $6 \mathrm{~L} / \mathrm{min}$ and then to $>10 \mathrm{~L} / \mathrm{min}$, the exhaled air distance was $0.22 \mathrm{~m}, 0.40 \mathrm{~m}$, respectively. ${ }^{[35]}$

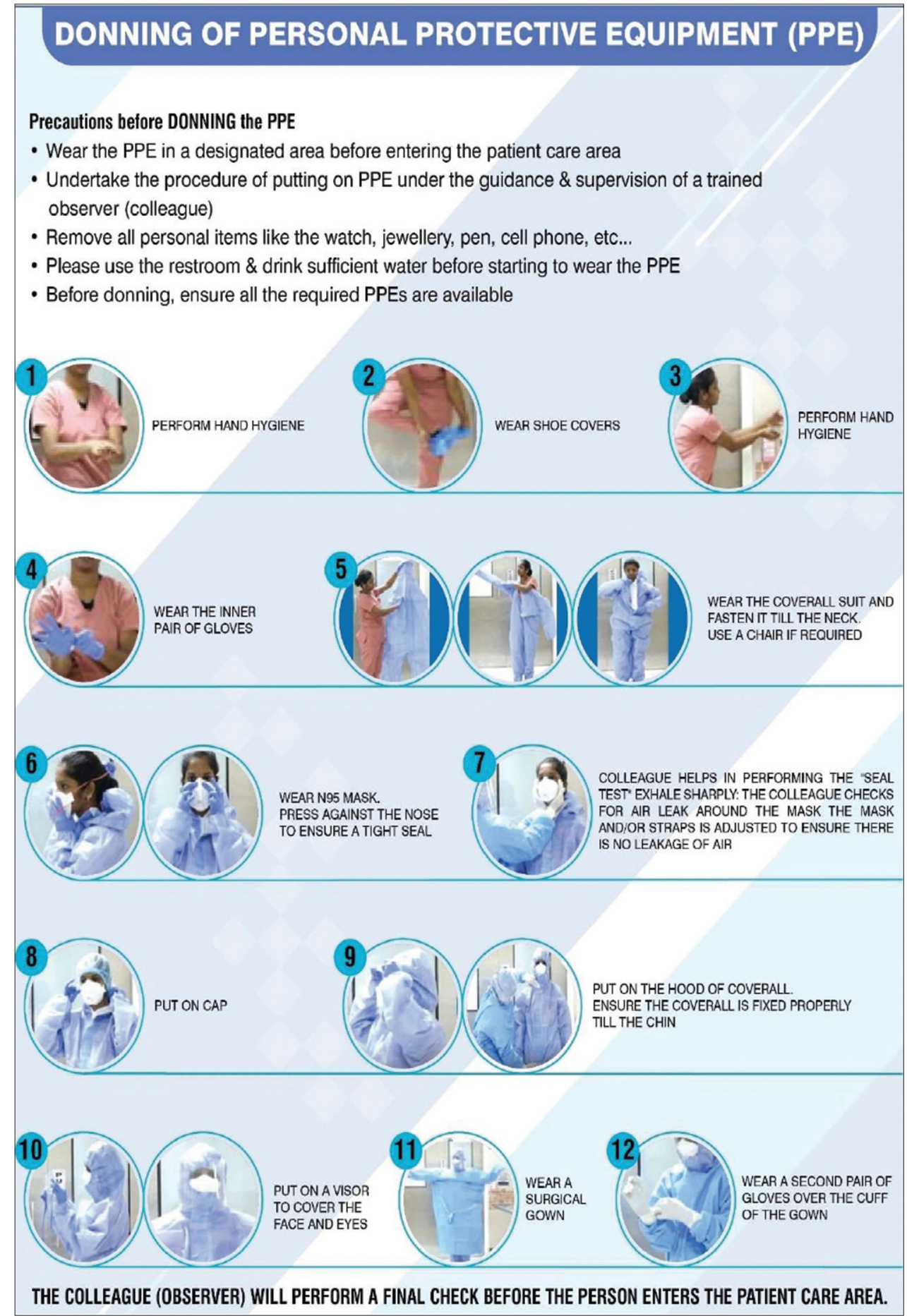

Figure 1: Donning of personal protective equipment (wearing the PPE) 


\section{Nebulizers}

The delivery of medications through nebulization can also cause dispersion of aerosolized particles in the proximity. The maximum exhaled air distance while using a jet nebulizer which is driven by air at $6 \mathrm{~L} / \mathrm{min}$ in healthy lung is $0.45 \mathrm{~m}$, while in severe lung injury, it can be beyond $0.8 \mathrm{~m} \cdot{ }^{[35,36]} \mathrm{A}$ review by Roy et al.$^{[34]}$ recommends that open nebulizers might be avoided rather manual in-line nebulization be considered. At present, there do not exist sufficient evidences either on the safety or on the risk of transmissibility of SARS-CoV-2 during nebulization in COVID-19 patients. ${ }^{\left[{ }^{[3]}\right.}$

\section{Noninvasive ventilation}

The evidence suggesting that NIV increases risk of acute respiratory infections is not strong. ${ }^{[37]}$ However, some studies show a significant association of NIV and risk of aerosolization. ${ }^{[38]}$
Raboud et al. ${ }^{[39]}$ in his study surveyed $624 \mathrm{HCWs}$ who were exposed to 45 intubated patients diagnosed with SARS. Twenty-six HCWs contracted SARS from a single patient. $38 \%$ of HCWs developed SARS exposed to NIV compared with $17 \%$ of those who did not, which was a statistically significant association.

Simonds et al. ${ }^{[40]}$ mentioned in their study that NIV application using vented masks is a droplet-generating procedure and not aerosol generating as produced droplets are $>10 \mu \mathrm{m}$. They compared the droplet generation using NIV and NIV with circuit modification done by inclusion of an exhalation filter. It was noted that the droplet count reduced by $1 \mathrm{~m}$ with NIV circuit modification.

\section{Suctioning}

Suctioning an intubated patient infected with SARS-COV-2 is a high-risk AGP ${ }^{[41]}$ Open suctioning of intubated patients' airways

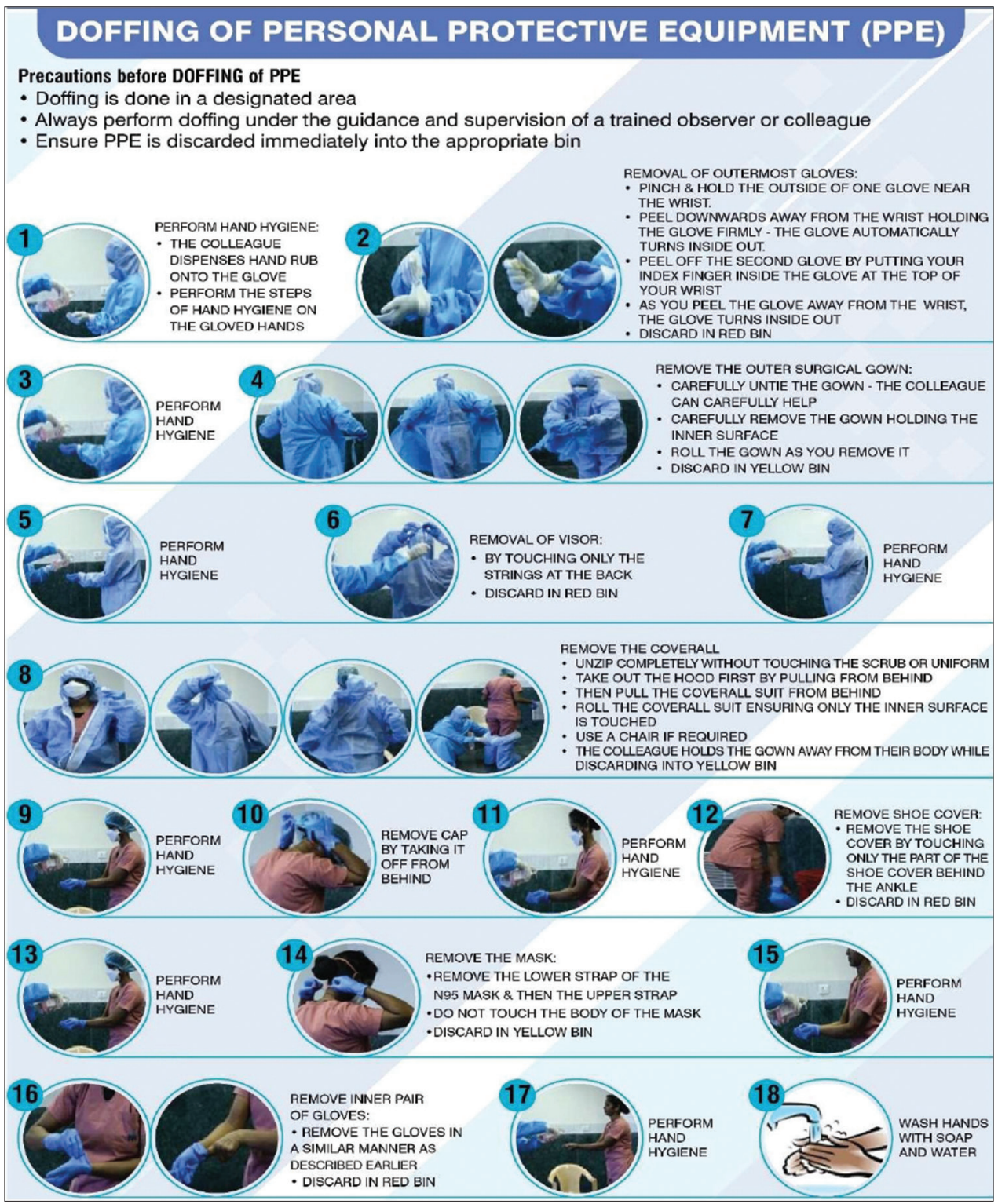

Figure 2: Doffing of personal protective equipment (removing the PPE) 
Kanchi, et al.: Respiratory system - The port of entry of SARS-COV-2 with special reference to aerosol management

involves disconnecting the tracheal tube from the ventilator, and this, or the suction itself, may lead to dispersal of aerosols from within the airway. Increased number of airborne particles near patients has been detected in association with airway suctioning. ${ }^{[2]}$ Close suctioning is recommended to reduce transmission of aerosols generated from patient's end. ${ }^{[43,44]}$

\section{Endotracheal intubation, extubation, tracheostomy}

The process of intubation for a COVID-19 patient is considered a high-risk procedure attributed to the high viral load due owing to the proximity of the HCPs to airway secretions. ${ }^{[45,46]}$ After tracheal intubation, exhaled normal cough could generate a plume that can disperse a distance of around $460 \mathrm{~mm} \cdot{ }^{[47]}$ The use of aerosol box to reduce the risk of transmission during intubation is recommended. ${ }^{[48]}$

Videolaryngoscopy is ideally recommended during intubation of COVID-19 patients, as it not only provides a better view of the glottis entrance but also increases the proximity

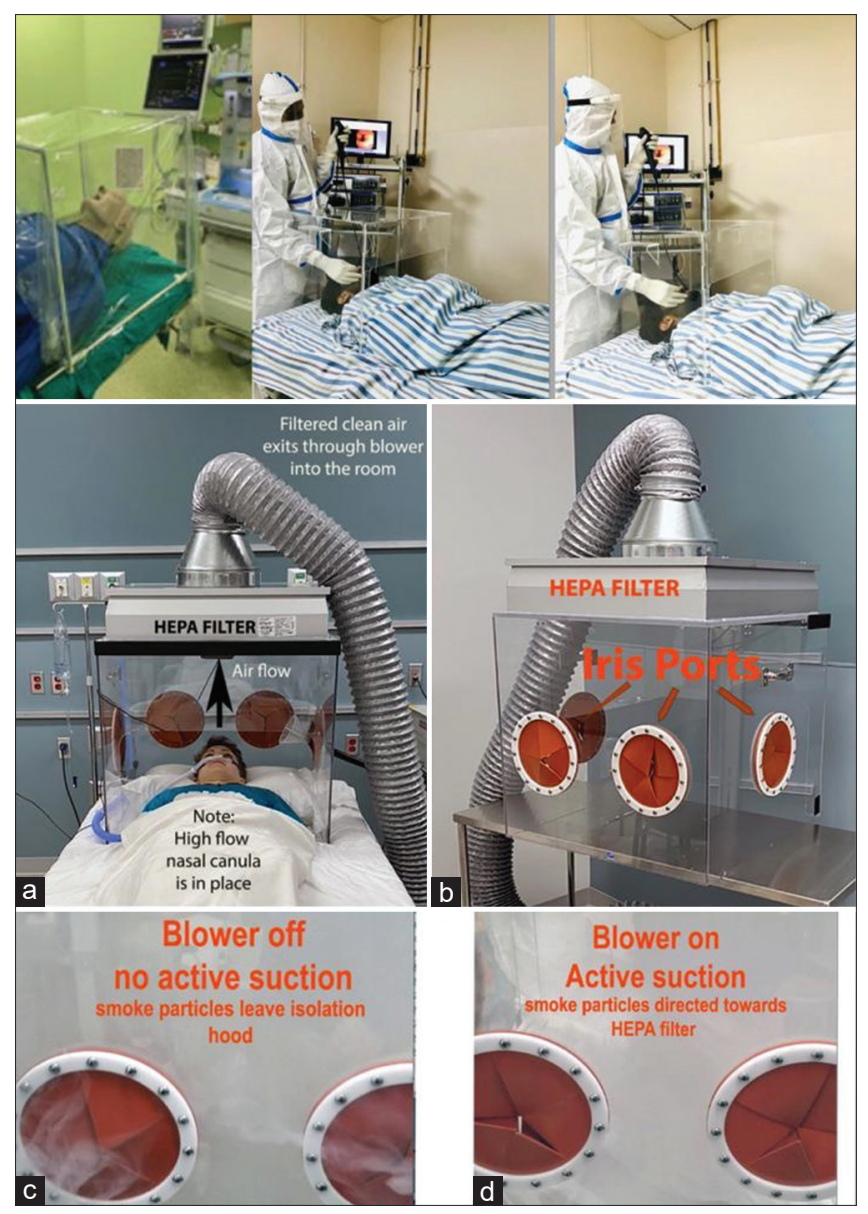

Figure 3: Illustration of aerosol box (reproduced with permission from ref.[57]) The top panel shows bronchoscopy being done in pulmonology lab using intubation box and personal protective equipment level 3 . The lower panel shows the use of aerosol hood demonstrating use of a high flow nasal cannula. (a). Rear-view (caudal) image of the aerosol hood, showing all iris port and the HEPA filter. (b) Images 30-40 s after igniting a smoke candle within the hood; left: no active suction. (c); right: active suction at $>10,000 \mathrm{~L} / \mathrm{min}(\mathrm{d})$. The active suction directs smoke particles towards the HEPA filter and releases clean air into the room (Courtesy: Dr. Balani) of the clinician and the patient's face, reducing risk of contamination. ${ }^{[49]}$

\section{Bronchoscopy}

In a study conducted by O'Neil et al., ${ }^{[50]}$ it was concluded that two procedures showed a significant increase in aerosol particle concentrations: nebulized medication administration and bronchoscopy; these undoubtedly pose a distinct risk of infection transmission to health-care personnel. Similar findings were reported by a study conducted by Doggett et al., ${ }^{[51]}$ wherein particle generation during and immediately following bronchoscope removal was compared to a preprocedure baseline. It was found that there is an increased aerosol production in $0.3 \mathrm{~mm}$ size particles. Similar findings were also reported by Lavoie et al..$^{[52]}$

\section{Bag mask ventilation}

BMV may also lead to dispersion of the exhaled plume for a distance of $220 \mathrm{~mm}$ transversely, while leakage at the patients' interface during the bag mask process may increase the dispersion distance by $340 \mathrm{~mm}$. However, the use of a filter and ensuring nonleakage at the interface reduces dispersion distance. ${ }^{[47]}$

\section{Cardiopulmonary resuscitation}

There is contrasting consensus whether CPR can be categorized under "AGP." The WHO has categorized it as AGP in the year 2007. However, it was delisted later. Since CPR not only consists of chest compressions, it can be considered as an AGP. In the study by Liu et al., chest compressions were found to be associated with infection risk. ${ }^{[53]}$ In an experimental study by Ott et al., they evaluated the spread of aerosol spread during CPR using dummy and cadaver models. ${ }^{[54]}$ In the dummy model, they nebulized disinfection detergents which could be
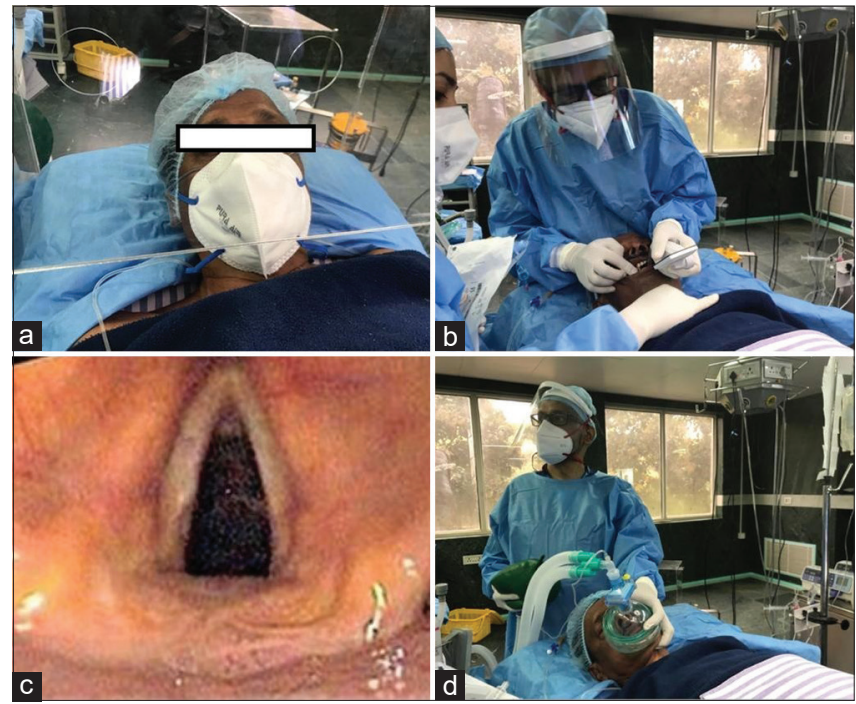

Figure 4: (a) Intubation box on a patient prior to endotracheal intubation. (b) Use of videolaryngoscope for endotracheal intubation. (c) View of glottis with a videolaryngoscope. (d) pre-oxygenation, bag mask ventilation is either avoided or done extremely gently with low flow of oxygen 
Kanchi, et al.: Respiratory system - The port of entry of SARS-COV-2 with special reference to aerosol management

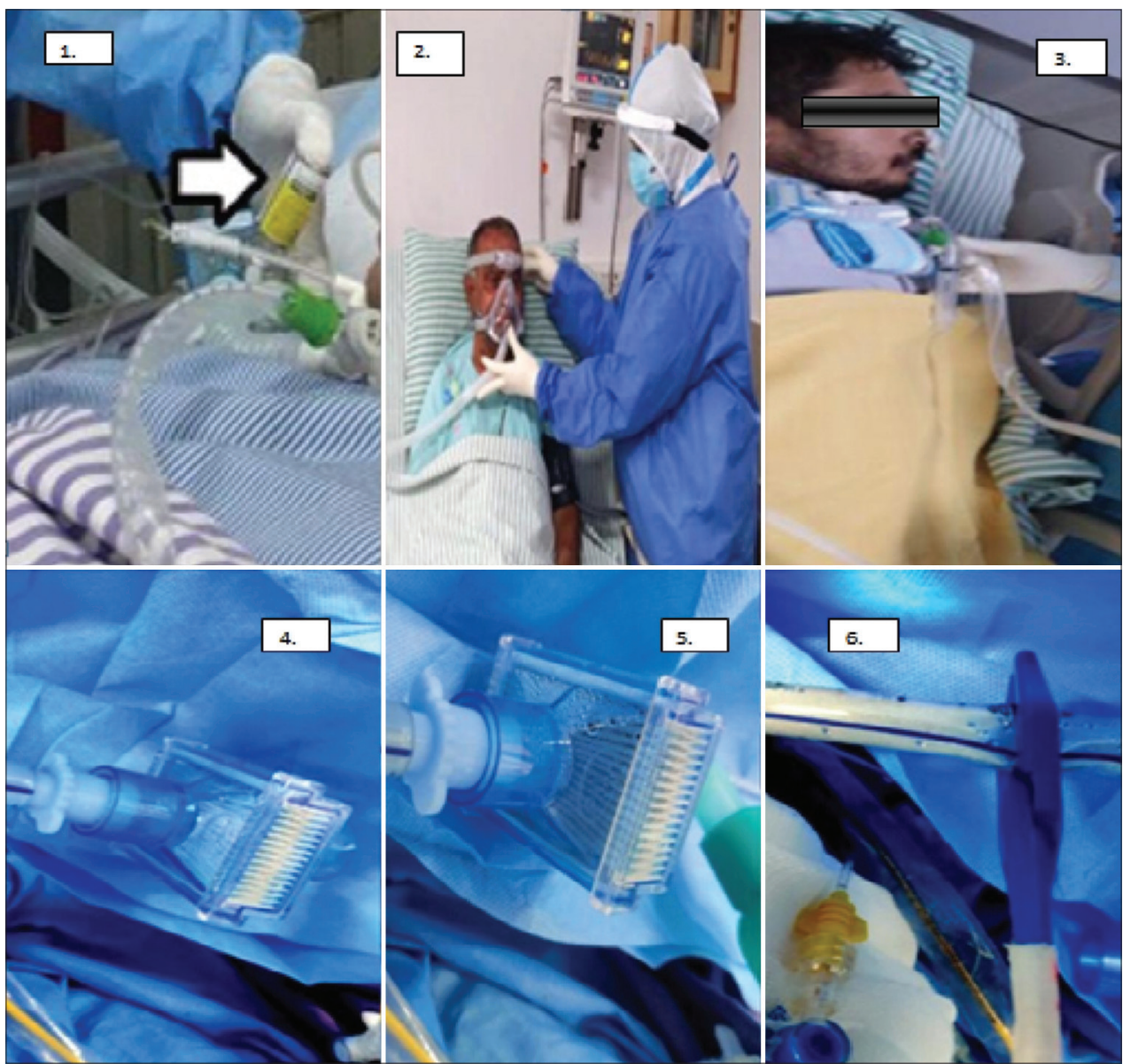

Figure 5: (1) In-line nebulization. (2) Noninvasive ventilation application with health-care professionals wearing level-3 personal protective equipment. (3) Closed suctioning. (4) Use of bacterial filters. (5) Disconnection of endotracheal tube must be done beyond HME or clamping endotracheal tube if disconnected before HME (6)

detected through ultraviolet rays. The nebulizer operated with a flow of $8 \mathrm{~L} / \mathrm{min}$. Chest compression was done and the aerosol plume was detected in compression-only CPR. However, addition of a face mask followed by application of oxygen reservoir mask reduced the aerosol spread. Similar findings were also reported in the cadaver model. ${ }^{[55]}$

\section{Infection control to minimize risk of hospital-based transmission}

Infection control practices during the management of COVID-19 are of prime importance to break the chain and reduce the risk of transmission of COVID-19 to the HCPs who are involved in the management of patients at various health-care settings.

\section{Infection control practices in our tertiary care multispecialty institution \\ Levels of PPE and application in COVID-19}

The levels of PPE to be used by HCPs at various departments whether direct or indirect contact with suspected/confirmed cases of patients is a major determinant that would help to contain the spread of the virus. At our health-care setup, three levels of PPE have been formulated along with the donning and doffing sequence. The sequences are on the basis of guidelines given by CDC. ${ }^{[56]}$ The PPE required has been divided into three levels $-1,2$, and 3 , according to the risk of exposure. Level 3 is recommended for the highest risk procedures. The entire setup is divided into the following categories, depending on which, correct and judicious use of PPE is carried out.

1. "High COVID risk" areas - patients in these areas have been admitted from the community

2. "Low COVID risk" areas - patients in these areas are of low risk for COVID based on history and a negative COVID polymerase chain reaction (PCR) result. Although the COVID PCR is negative, PPE based on the type of exposure is required.

Level 3 PPE: Steps for donning (putting on) the PPE [Figure 1]. This should be done outside the patient care area.

Level 3 PPE: Doffing (removing) of PPE [Figure 2] reproduced with permission from Dr. Vijay Richard.

The use of aerosol box, intubation box, and respiratory care procedures is illustrated in Figures 3-5. Figure 6 shows the Code Blue protocol in COVID-19 patients at our hospital. 
Kanchi, et al.: Respiratory system - The port of entry of SARS-COV-2 with special reference to aerosol management

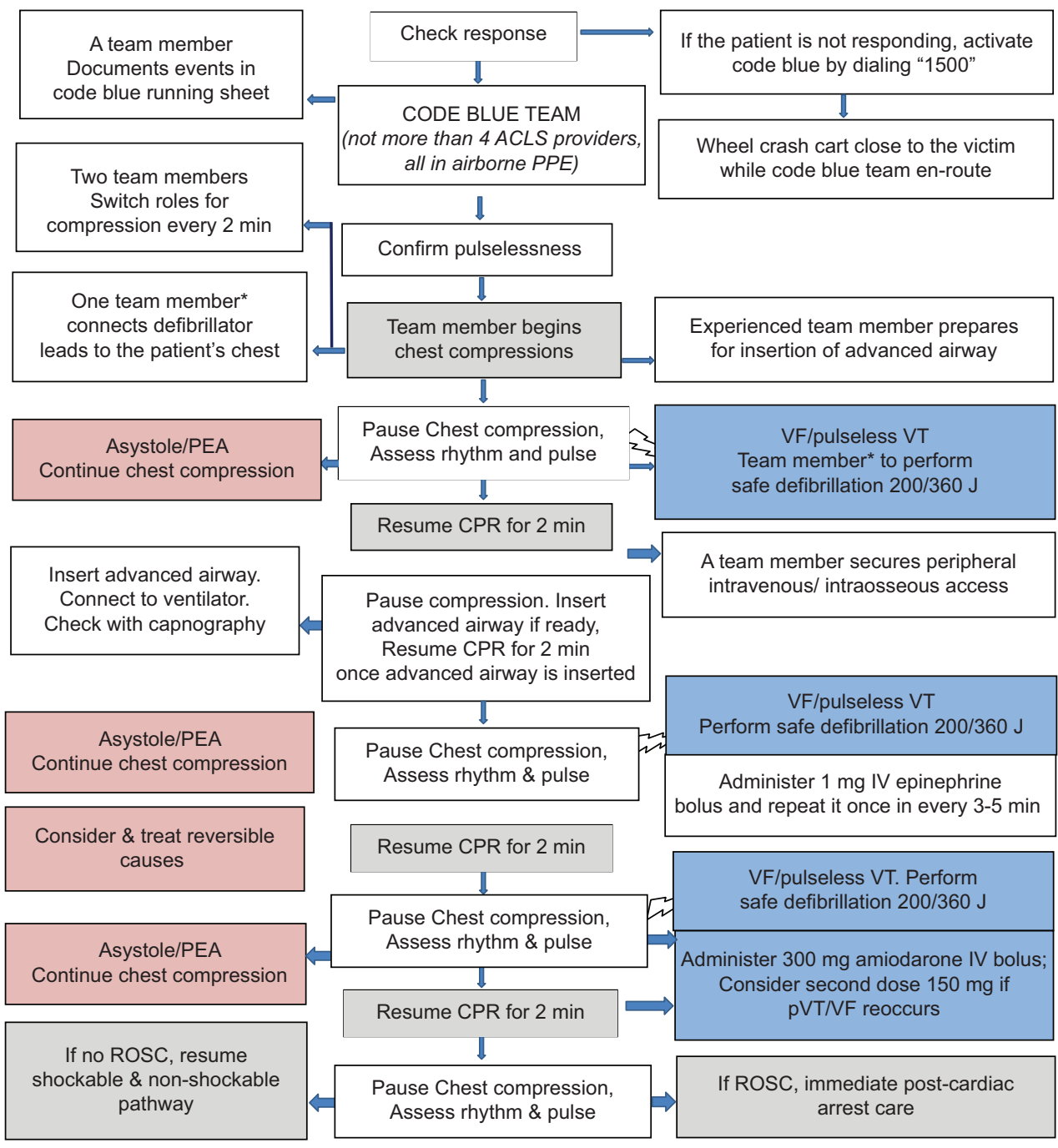

Same team member

Five sets of PPE are stored at all the in-patient units of the hospital and is kept reserved for code blue

Figure 6: Code blue protocol during COVID-19 pandemic for in-hospital cardiac arrest

\section{Surgical smoke evacuator}

Surgical smoke evacuators (SSE) consist of a high flow negative pressure pump that provides negative airflow rates that are 25-40 times greater than the standard suction used in hospitals. It also consists of an ultra-low particulate air filter and a disposable plastic suction hose. An SSE may be used as a mechanical barrier during intubation and extubation. The aerosolized viral load which is generated during airway management is captured and diverted from the HCPs. A SSE can be thought of as a "vacuum cleaner" and it follows the well-accepted infection control principles of "source control" and "negative pressure respiratory isolation." [58]

\section{ConcLusion}

Coronavirus is contagious and spreads through respiratory tract. Hence, the knowledge of various AGPs and measures that must be taken to prevent spread is of utmost importance to prevent its spread to the HCPs.

\section{Financial support and sponsorship} Nil.

\section{Conflicts of interest}

There are no conflicts of interest.

\section{ReFERENCES}

1. Wu F, Zhao S, Yu B, Chen YM, Wang W, Song ZG, et al. Author correction: A new coronavirus associated with human respiratory disease in China. Nature 2020;580:E7.

2. Reusken CB, Buiting A, Bleeker-Rovers C, Diederen B, Hooiveld M, Friesema I, et al. Rapid assessment of regional SARS-CoV-2 community transmission through a convenience sample of healthcare workers, the Netherlands, March 2020. Euro Surveill 2020;25:2000334.

3. Behzad S, Aghaghazvini L, Radmard AR, Gholamrezanezhad A. Extrapulmonary manifestations of COVID-19: Radiologic and clinical overview. Clin Imaging 2020;66:35-41.

4. Cascella M, Rajnik M, Cuomo A, Dulebohn SC, Napoli RD. Features, Evaluation and Treatment Coronavirus (COVID-19). In: StatPearls. Treasure Island (FL): StatPearls Publishing; 2020 January. Available from: https://www.ncbi.nlm.nih.gov/books/NBK554776/. [Last 
accessed on 2020 Nov 11; Last updated on 2020 Jul 04].

5. Gupta A, Madhavan MV, Sehgal K, Nair N, Mahajan S, Sehrawat TS, et al. Extrapulmonary manifestations of COVID-19. Nat Med 2020;26:1017-32.

6. Arabi YM, Arifi AA, Balkhy HH, Najm H, Aldawood AS, Ghabashi A, et al. Clinical course and outcomes of critically ill patients with Middle East respiratory syndrome coronavirus infection. Ann Intern Med 2014;160:389-97.

7. Wiersinga WJ, Rhodes A, Cheng AC, Peacock SJ, Prescott HC. Pathophysiology, transmission, diagnosis, and treatment of coronavirus disease 2019 (COVID-19): A review. JAMA 2020;324:782-93.

8. Bosch BJ, van der Zee R, de Haan CA, Rottier PJ. The coronavirus spike protein is a class I virus fusion protein: Structural and functional characterization of the fusion core complex. J Virol 2003;77:8801-11.

9. Li W, Moore MJ, Vasilieva N, Sui J, Wong SK, Berne MA, et al. Angiotensin-converting enzyme 2 is a functional receptor for the SARS coronavirus. Nature 2003;426:450-4.

10. Zhou P, Yang XL, Wang XG, Hu B, Zhang L, Zhang W, et al. A pneumonia outbreak associated with a new coronavirus of probable bat origin. Nature 2020; 579:270-3.

11. Cao W, Li T. COVID-19: towards understanding of pathogenesis. Cell Res 2020;30:367-9.

12. Bombardini T, Picano E. Angiotensin-converting enzyme 2 as the molecular bridge between epidemiologic and clinical features of COVID-19. Can J Cardiol 2020;36:784.e1-0.

13. Wrapp D, Wang N, Corbett KS, Goldsmith JA, Hsieh CL, Abiona O, et al. Cryo-EM structure of the 2019-nCoV spike in the prefusion conformation. Science 2020;367:1260-3.

14. Li F, Li W, Farzan M, Harrison SC. Structure of SARS coronavirus spike receptor-binding domain complexed with receptor. Science 2005;309:1864-8.

15. NiW, Yang X, Yang D, Bao J,LiR, XiaoY,etal.Role of angiotensin-converting enzyme 2 (ACE2) in COVID-19. Crit Care 2020;24:422.

16. Perrotta F, Matera MG, Cazzola M, Bianco A. Severe respiratory SARS-CoV2 infection: Does ACE2 receptor matter? Respir Med 2020;168:105996.

17. Harding H, Broom A, Broom J. Aerosol-generating procedures and infective risk to healthcare workers from SARS-CoV-2: The limits of the evidence. J Hosp Infect 2020;105:717-25.

18. Howard BE. High-risk aerosol-generating procedures in COVID-19: Respiratory protective equipment considerations. Otolaryngol Head Neck Surg 2020;163:98-103.

19. Tran K, Cimon K, Severn M, Pessoa-Silva CL, Conly J. Aerosol generating procedures and risk of transmission of acute respiratory infections to healthcare workers: A systematic review. PLoS One 2012;7:e35797.

20. Wong KC, Leung KS. Transmission and prevention of occupational infections in orthopaedic surgeons. J Bone Joint Surg Am 2004;86:1065-76.

21. Wang D, Hu B, Hu C, Zhu F, Liu X, Zhang J, et al. Clinical characteristics of 138 hospitalized patients with 2019 novel coronavirus-infected pneumonia in Wuhan, China. JAMA 2020;323:1061-9.

22. Dhand R, Li J. Coughs and sneezes: Their role in transmission of respiratory viral infections, including SARS-CoV-2. Am J Respir Crit Care Med 2020;202:651-9.

23. Sommerstein R, Fux CA, Vuichard-Gysin D, et al. Risk of SARS-CoV-2 transmission by aerosols, the rational use of masks, and protection of healthcare workers from COVID-19. Antimicrob Resist Infect Control 2020;100:9.

24. Wei J, Li Y. Airborne spread of infectious agents in the indoor environment. Am J Infect Control 2016;44:S102-8.

25. Bourouiba L. Turbulent gas clouds and respiratory pathogen emissions: Potential implications for reducing transmission of COVID-19. JAMA 2020;323:1837-8.

26. Tang JW, Liebner TJ, Craven BA, Settles GS. A schlieren optical study of the human cough with and without wearing masks for aerosol infection control. J R Soc Interface 2009;6 Suppl 6:S727-36.

27. Anfinrud P, Stadnytskyi V, Bax CE, Bax A. Visualizing speech-generated oral fluid droplets with laser light scattering. $\mathrm{N}$ Engl J Med 2020;382:2061-3.

28. Weaver GH. Droplet infection and its prevention by the face masks.
J Infect Dis 1919;24:218-30.

29. Setti L, Passarini F, De Gennaro G, Barbieri P, Perrone MG, Borelli M, et al. Airborne transmission route of COVID-19: Why 2 meters/ 6 feet of inter-personal distance could not be enough. Int J Environ Res Public Health 2020;17:2932.

30. Kumar GP, Kulkarni AP, Govil D, Dixit SB, Chaudhry D, Samavedam S, et al. Airway management and related procedures in critically Ill COVID-19 patients: Position statement of the Indian society of critical care medicine. Indian J Crit Care Med 2020;24:630-42.

31. Panuganti BA, Pang J, Califano J, Chan JY. Procedural precautions and personal protective equipment during head and neck instrumentation in the COVID-19 era. Head Neck 2020;42:1645-51.

32. Infection Prevention and Control of Epidemic- and Pandemic-Prone Acute Respiratory Infections in Health Care. Geneva: World Health Organization; 2014.

33. van Doremalen N, Bushmaker T, Morris DH, Holbrook MG, Gamble A, Williamson BN, et al. Aerosol and surface stability of SARS-CoV-2 as compared with SARS-CoV-1. N Engl J Med 2020;382:1564-7.

34. Roy A, Singh A, Khanna P. Oxygen delivery devices in COVID-19 patients: Review and recommendation. Bali J Anaesthesiol 2020;4 Suppl S1:3-7.

35. Hui DS, Chan MT, Chow B. Aerosol dispersion during various respiratory therapies: A risk assessment model of nosocomial infection to health care workers. Hong Kong Med J 2014;20 Suppl 4:9-13.

36. Katiyar SK, Katiyar S. Nebulization in the pandemic of coronavirus disease 2019. Indian J Allergy Asthma Immunol 2020;34:8-14.

37. Xia JG, Zhao JP, Cheng ZS, Hu Y, Duan J, Zhan QY. Non-invasive respiratory support for patients with novel coronavirus pneumonia: Clinical efficacy and reduction in risk of infection transmission. Chin Med J (Engl) 2020;133:1109-11.

38. Esquinas AM, Egbert PS, Scala R, Gay P, Soroksky A, Girault C. Noninvasive mechanical ventilation in high-risk pulmonary infections: A clinical review. Eur Resp Rev 2014;23:427-38.

39. Raboud J, Shigayeva A, McGeer A, Bontovics E, Chapman M, Gravel D, et al. Risk factors for SARS transmission from patients requiring intubation: A multicentre investigation in Toronto, Canada. PLoS One 2010;5:e10717.

40. Simonds AK, Hanak A, Chatwin M, Morrell M, Hall A, Parker KH, et al. Evaluation of droplet dispersion during non-invasive ventilation, oxygen therapy, nebuliser treatment and chest physiotherapy in clinical practice: Implications for management of pandemic influenza and other airborne infections. Health Technol Assess 2010;14:131-72.

41. Cook TM. Personal protective equipment during the coronavirus disease (COVID) 2019 pandemic - A narrative review. Anaesthesia 2020;75:920-7.

42. Chung FF, Lin HL, Liu HE, Lien AS, Hsiao HF, Chou LT, et al. Aerosol distribution during open suctioning and long-term surveillance of air quality in a respiratory care center within a medical center. Respir Care 2015;60:30-7.

43. De Seta D, Carta F, Puxeddu R. Management of tracheostomy during COVID-19 outbreak: Heat and moisture exchanger filter and closed suctioning system. Oral Oncol 2020;106:104777.

44. Vargas M, Servillo G. Closed-suction System for intubated COVID-19 patients with the use of an ultrasound probe cover. Anesthesiology 2020;133:687-9.

45. Orser Beverley A. Recommendations for endotracheal intubation of COVID-19 patients. Anesth Analg 2020;130:1109-10.

46. Odor PM, Neun M, Bampoe S, Clark S, Heaton D, Hoogenboom EM, et al. Anaesthesia and COVID-19: Infection control. Br J Anaesth 2020; $125: 16-24$

47. Chan MTV, Chow BK, Lo T, Ko FW, Ng SS, Gin T, et al. Exhaled air dispersion during bag-mask ventilation and sputum suctioning - Implications for infection control. Sci Rep 2018;8:198.

48. Vijayaraghavan S, Puthenveettil N. Aerosol box for protection during airway manipulation in COVID-19 patients. Indian J Anaesth 2020;64:S148-S149.

49. Zeidan A, Bamadhaj M, Al-Faraidy M, Ali M. Videolaryngoscopy intubation in patients with COVID-19: How to minimize risk of aerosolization? Anesthesiology 2020;133:481-3.

50. O’Neil CA, Li J, Leavey A, Wang Y, Hink M, Wallace M, et al. Centers 
for disease control and prevention epicenters program. Characterization of aerosols generated during patient care activities. Clin Infect Dis 2017;65:1335-41.

51. Doggett N, Chow CW, Mubareka S. Characterization of experimental and clinical bioaerosol generation during potential aerosol-generating procedures. Chest 2020;158:2467-73.

52. Lavoie J, Marchand G, Cloutier Y, Hallé S, Nadeau S, Duchaine C, et al. Evaluation of bioaerosol exposures during hospital bronchoscopy examinations. Environ Sci Process Impacts 2015;17:288-99.

53. Liu W, Tang F, Fang LQ, Vlas SJ, Ma HJ, Zhou JP. Riskfactors for SARS infection among hospital healthcare workers in Beijing: A case control study. Trop Med Int Health 2009;14:52-9.

54. Ott M, Milazzo A, Liebau S, Jaki C, Schilling T, Krohn A, et al. Exploration of strategies to reduce aerosol-spread during chest compressions: A simulation and cadaver model. Resuscitation 2020;152:192-8.

55. World Health Organization. Coronavirus Disease 2019 (COVID-19) Situation Report - 82. Geneva: WHO; 2020. Available from: https://www.who.int/docs/default-source/coronaviruse/situationreports/20200411-sitrep-82-covid-19.pdf. [Last accessed on 2021 Feb 07].

56. Centers for Disease Control and Prevention. Using Personal Protective Equipment (PPE). Available from: https://www.cdc.gov/coronavirus 2019-ncov/hcp/using-ppe.html. [Last accessed on 2021 Feb 07; Last updated on 2020 Aug 19].

57. Singh B, Singla SL, Gulia P, Kumar A, Bhanwala R. Aerosol containment device for use on suspected COVID-19 patients. Indian J Anaesth 2020;64:S154-S156.

58. Gonzalez R, Schaefer John J, Krohner Robert G. Simple Method for Reducing Risk for Aerosolized COVID-19 Transmission During Intubation Aand Extubation: The Surgical Smoke Evacuator. Available from: https://www.anesthesiologynews.com/ Policy-and-Management/Article/08-20/A-Simple-Method-for-Redu cing-Risk-for-Aerosolized-COVID-19-Transmission-During-Intub ation-and-Extubation-The-Surgical-Smoke-Evacuator/59168. [Last accessed on 2020 Nov 11]. 